\title{
Two Fundamentally Different Perspectives on Time
}

\author{
Jesse M. Mulder ${ }^{1}$
}

Received: 17 June 2016/Accepted: 17 August 2016/Published online: 24 August 2016

(C) The Author(s) 2016. This article is published with open access at Springerlink.com

\begin{abstract}
Frege taught us how to understand one form of predication: an atemporal one. There is also a different, temporal form of predication, which I briefly introduce. Accordingly, there are two fundamentally different approaches to time: a reductive one, aiming to account for time in terms of Frege's atemporal predication, and a non-reductive one, insisting that the temporal form of predication is sui generis, and that time is to be understood in its terms. I do not directly argue for or against reductionism in this paper. Rather, by evaluating the debates on endurantism-perdurantism, A-theory-B-theory, and presentism-eternalism, I argue that these debates, although aiming to be fundamental, largely boil down to mere quarrels between alternative reductive approaches. We should take notice of this fact and reorient ourselves within the debate on time accordingly: the real issue is whether we should reduce or not. I briefly sketch in what sense endurantism, A-theory, and presentism may be developed on a properly anti-reductionist basis.
\end{abstract}

Keywords Time $\cdot$ Presentism · A-theory $\cdot$ Endurantism $\cdot$ Predication . Reductionism

\section{Introduction}

With this article, I aim to contribute to clarifying what exactly is at stake in (large portions of) contemporary philosophy of time. In particular, I will argue that most disputes on the nature of time in the end boil down to a clash between two radically different and incompatible conceptions of time. The first conception can be characterized as geometrical in nature: time is understood as a dimension of reality that provides

Jesse M. Mulder

j.m.mulder@uu.nl

1 Department of Philosophy, Utrecht University, Janskerkhof 13a, 3512BL Utrecht,

The Netherlands 
locations for reality's inhabitants in much the same way spatial dimensions do. The second conception takes time to be a sui generis form of being, or, as I will say, a formal concept characterizing a sui generis form of predication. That temporal form of predication constitutes the unity of temporal truths or facts, which differs from the unity of atemporal truths or facts (such as geometrical truths). Juxtaposing these two conceptions of time, it transpires that the first, geometrical approach is reductive in the following sense: it takes the unity of temporal truths or facts, in the final analysis, to be the same as that of atemporal truths or facts. The reductive view thus aims to account for time in terms of an atemporal form of predication, while its non-reductive counterpart recognizes a specifically temporal form of predication. ${ }^{1}$

I will explain and defend this way of framing the metaphysical discussion on time in what follows. It is not my aim to make a case for or against either one of these perspectives on time, although my presentation is not neutral-I take the antireductionist approach to be correct, but I leave my arguments to that effect for another occasion. My purpose here is, rather, to contribute to a clearer understanding of what exactly is at stake in the relevant parts of the philosophy of time.

The plan is as follows. I first sketch the anti-reductionist and reductionist positions (in Sects. 2, 3), and then zoom in on three strands of debate in contemporary philosophy of time: endurantism-perdurantism, A-theory-B-theory, and eternalism-presentism (in Sects. 4, 5,6). In particular, my discussion of A-theory in Sect. 5 centers around Fine's (2005b) classification thereof, and on the general idea of the passage of time. And my discussion of presentism in Sect. 6 critically assesses the supposed unity of present-tensed truths that many contemporary writers adopt from Arthur Prior's (1957, 1967, 1968b) tense logic.

As it turns out, these three debates largely boil down to disagreements within a reductionist setting, and thus fail to capture the fundamental issue of whether or not we can reduce-despite the strong anti-reductionist leanings of most defenders of endurantism, A-theory, and presentism. Still, endurantism, A-theory and presentism do form part of a non-reductive view: I briefly sketch how they relate to the temporal form of predication in Sect. $7 .^{2}$

\section{The Original Temporal Nexus}

One of Frege's important contributions to philosophy is his identification and clarification of a particular form of predication: the one that unites concepts (Begriffe) with objects (Gegenstände) in a way that can be adequately characterized

\footnotetext{
${ }^{1}$ It will be clear, from this statement of my aims in this paper, that I assume the philosophy of time to be investigating the objective nature of time itself-not our experience of time, or something such. In that sense, I assume some form of realism-testified by my seemingly sloppy use of the phrase "temporal truths or facts". I intend to show that there are, ultimately, two ways of spelling out such a realism about time: a reductive and a non-reductive one. For reasons of scope, I cannot inquire whether this assumption of realism is justified.-Thanks to an anonymous referee for pointing out the need to clarify this.

2 My discussion proceeds in large part in terms of (temporal and atemporal) truths exemplifying diverse forms of predication. However, I do not mean to encourage a 'linguistic' reading of these locutions. One may substitute "judgment" or "instantiation" or "exemplification" for "predication", and "(true) thought" or "(true) proposition" or "fact" for "truth". I believe (but will not argue here) that it all comes down to the same. See my $(2013,2014)$.
} 
as function application. His concomitant concepts Begriff and Gegenstand are categories, or formal concepts: they characterize the form of predication Frege was concerned with. ${ }^{3}$ Many analytic philosophers explicitly or implicitly take the Fregean form of predication as the only form of predication, or at least as the only fundamental form of predication. For reasons that will soon become apparent, I will call this form of predication atemporal predication.

It will be useful to clarify the relation of these Fregean categories to his form of predication. A basic Fregean thought consists of a concept applied to the right number of objects. That is the general form of Fregean thoughts, which gives rise to a hierarchy of more specific forms (such as quantified thoughts and higher-order thoughts). This general form of Fregean thoughts thus includes a distinction between thought-elements of the concept-kind and those of the object-kind. Nothing is a Fregean thought if it does not include a concept and (the right number of) objects, and conversely, nothing can be a concept (or an object) in this formal sense if it does not figure in Fregean thoughts. It is in this sense that the Fregean form of predication gives rise to formal categories.

I will shortly introduce another form of predication that fundamentally differs from Frege's atemporal one. It is a specifically temporal form of predication, and it comes with its own formal categories-temporal categories. ${ }^{4}$ What I aim to show in this paper is that the question whether this temporal form of predication is fundamental or not is crucial for the metaphysical debate on time. If the temporal form of predication is indeed fundamental, a philosophical account of time basically consists in clarifying that form of predication and its concomitant categories, analogous (though not similar) to Frege's clarification of atemporal predication. If it is not, we are in need of a reductive account of the temporal form of predication and its categories, in terms of the Fregean form of atemporal predication. In the first case, we aim for a non-reductive theory of time, in the second case for a reductive theory. Let us see what it exactly is that can or cannot be reduced.

Our temporal reality is occupied by interacting, moving, changing objects. As they interact, change, and move about, time passes. We can contrast this reality with an atemporal reality we may pretend to imagine. Such an atemporal reality is not a covertly temporal reality in which everything stays the same (if such a thing is possible at all) but rather a reality to which no temporal concepts apply at all. Let us take the Euclidean plane as an example. It includes points, lines, circles, triangles, and all sorts of other geometrical figures. These objects do not interact, move, or change-and that is no unfortunate accident but rather one of the constitutive characteristics of such geometrical entities.

Truths about the geometrical inhabitants of our imagined atemporal reality exemplify Frege's atemporal form of predication (indicated by [square brackets]): "Triangle $t$ [is] right-angled", "Circle $c$ [lies within] square $s$ ", etc. Truths about physical objects that inhabit reality exemplify a different form of predication

\footnotetext{
3 For a much more detailed description of this particular aspect of Frege's theory of predication, see Thompson (2008, Introduction) and Mulder (2014, esp. chs. 3 and 4).

${ }^{4}$ For a detailed development and defense of this form of predication and the categories that come with it, see Rödl (2012). This paper is mainly inspired by Rödl's work.
} 
(indicated by the absence of square brackets): "the glass is on the table", "the glass is falling to the ground", "the glass has fallen to the ground", "the glass was on the table".

The most striking prima facie difference between these two forms of predication is the following. The atemporal form of predication is uniform: there is only one way in which it can unite a given predicate (a Begriff) with a (suitable) number of given objects (Gegenstände). Not so for the temporal form of predication, which is differentiated in two ways. First, it is differentiated in tense: object(s) and predicate can be joined in a present-tensed way and in a past-tensed way. ${ }^{5}$ However, these two ways are intimately connected: one can say the very same thing by first saying "the glass is on the table" and later saying "the glass was on the table". ${ }^{6}$ After all, if I yesterday stated that "the glass is on the table", you can question my statement today by claiming that "the glass was not on the table". In such a case, we are in genuine disagreement only if, using the latter sentence today, you are negating the very same thought I expressed yesterday, using the former sentence.-It is clear, therefore, that this form of predication, unlike the atemporal one, cannot be adequately characterized as function application.

Secondly, the temporal form of predication is also differentiated in aspect: it can unite object(s) and predicate in a progressive and in a perfective way. Again, these two ways are intimately, but differently, connected. The progressive "the glass is falling to the ground" expresses a process that is still unfolding, one that reaches its completion when "the glass has fallen to the ground" is true. However, there is no guarantee that it does-for instance, someone may catch the glass in mid-air, in which case only the past-tensed progressive "the glass was falling to the ground" is true, and not the perfective "the glass has fallen to the ground". 7 The latter does imply the former, however.

Perhaps this example is found to be artificial: the process in question could also be described simply as "the glass is falling", in which case there seems to be no natural state of completion implied (although one could argue that there still is, given the nature of falling, or, more generally, the nature of gravity). A better example would be "Jim is crossing the street", which could be frustrated by his being hit by lightning when half-way. Such a process does imply a state of completion (with Jim on the other side of the street). However, this example depends on Jim's intentions, which invites questions concerning the nature of intentional action that fall outside of the scope of this article. But perhaps the following will do: suppose I take an ice-cube out of the freezer and put it on my desk. "The ice is melting" now gives expression to what is happening to the ice (I usually keep my desk under normal atmospheric pressure at around room temperature). After a while, "The ice has melted" expresses that the process of melting has come to its completion. But I could, of course, have put the ice cube

\footnotetext{
5 For reasons of scope, and to keep things relatively simple, I omit discussion of the future tense along with the many interesting questions concerning (in)determinism it invites.

${ }^{6}$ I present my examples by using quoted sentences, but, as the present point illustrates, I intend to thereby present thoughts (statements, propositions), and not the sentences themselves. That is why I can say that by using two different sentences one can say the same thing.

${ }^{7}$ In linguistics, this is called the 'imperfective paradox'. See Dowty (1977).
} 
back into the freezer at any point during the melting process, thereby interrupting it before completion. ${ }^{8}$

The temporal form of predication thus distinguishes processes from states: states require, for their expression, only a differentiation in tense, while processes allow for a further differentiation in aspect. Moreover, processes always already include some duration: if a glass is falling off the table (or if ice is melting), this implies that there has already been some stretch of falling (or of melting) - however short it may be. Of course, processes can be interrupted at any stage: something may stop the glass from falling further, or stop the ice from melting further. This is different from preventing the glass from falling at all, or preventing the ice from melting in the first place. Wherever there is a process, there is some duration. Thus, wherever there is a process, there is persistence of the objects involved: they remain the same over time as the bearers of that process. ${ }^{9}$

At this point, these observations are just that-observations. One may be inclined to think that they can be nicely captured in terms of the Fregean, atemporal form of predication, or one may be inclined to take these observations as underwriting one or another version of, say, A-theory or presentism or endurantism familiar from the literature. In what follows, I hope to contribute to a better understanding of how we arrive at either of these two kinds of views. In order to be able to do so, however, we first have to clarify what exactly these observations can tell us before we start interpreting them in one of these two ways. If we thus take the prima facie differences between our two forms of predication seriously, we can distill a couple of categories that attach to the temporal form of predication, much in the way in which Frege's categories of Begriff and Gegenstand can be distilled from his atemporal form of predication.

First, there is the category of substance: the analogue of Frege's Gegenstand category. Then, we have two categories of predicables, state and activity: analogues of Frege's Begriff category. The difference between these two categories is indeed a formal one: state-ascriptions, such as "being on", only allow for (and require) tensed differentiation, while activity-ascriptions, such as "falling to(wards)" also allow for (and require) aspectual differentiation. ${ }^{10}$

\footnotetext{
8 Thanks to an anonymous referee for pointing out the need for more examples here.

9 Those rejecting the very idea of persisting objects will object. They will take the phenomenon of persistence as something unreal, to be explained in different terms. One way to do so would be, perhaps, in terms of pure processes: processes that do not attach to any underlying object, but only to further processes (see, e.g., Whitehead (1929) and his contemporary followers, including Sellars (1981a, b, c), Rescher (1996, 2000), Bickhard (2011a, b)). That would be a limiting case of endorsing the temporal form of predication I am sketching here. But others will be skeptical of such a notion of process as well. As I said at the outset, I am assuming a generic form of realism concerning time, so I will ignore those questioning that reality. Yet one may acknowledge the reality of time and still resist the thought that objects persist by being cross-temporally identical. We will see below that the reductive perspective on time, which attempts to capture the forms of thought based on the temporal form of predication in atemporal terms, naturally takes such a shape.

${ }^{10}$ Further categories can be distilled here. The counterpart of an activity (e.g., "falling") is a process, that can be the subject of state-ascriptions of its own ("the falling is/was fast"). Then, activities and substances can be combined modally: "the glass can fall" - these are powers. These further formal concepts, however, are not my present topic. See Rödl (2012, esp. Part II) for detailed discussion.
} 
These temporal categories collectively constitute what I call the original temporal nexus: a family of formal concepts centered around the form of predication that constitutes the unity of temporal thoughts, analogous to the family of formal concepts centered around Frege's form of predication, which constitutes the unity of Fregean thoughts (Gedanken). The temporal categories cannot be understood in isolation from each other; they form a conceptual circle that can only be elucidated 'from within' - for the same reason why Frege's more abstract system of categories forms such a conceptual circle: they all pertain to one and the same form of predication.

So much for an impressionistic sketch of the form of predication that constitutes the basis of the original temporal nexus. The temporal anti-reductionist holds that this form of predication is fundamental. Let us call his view the original view. At this point, I haven't filled in the details of this original view. It is natural to think that A-theory and/or endurantism and/or presentism are ways of defending this original view, and it is precisely my aim to assess to what extent that is true in the rest of this paper. The temporal reductionist, on the other hand, thinks that the relevant temporal concepts and distinctions can be captured, ultimately, in terms of Frege's unitary, atemporal form of predication. I will call this the reductive view. Let us see how such a reduction might work.

\section{Temporal Reductionism}

The thought underlying the reductive view is that the original temporal nexus, which we sketched in barest outline above, needs to be accounted for: it should be understood in terms that do not themselves reside in that very conceptual nexus. Differently put, the sketched temporal conceptual order is to be grounded in an underlying real order that can be fully understood by using only Frege's atemporal form of predication. That is, roughly, what I have in mind when I call the intended understandings of time reductive: the original temporal nexus is not accepted as capturing a sui generis defining aspect of reality. Only Frege's atemporal nexus is thus accepted. ${ }^{11}$

There is, perhaps, no better way of sketching the picture such a reductive approach to time departs from than by quoting the opening passage of David Lewis's On the Plurality of Worlds. It nicely displays the thought of someone to whom the reductive view comes very naturally:

The world we live in is a very inclusive thing. Every stick and every stone you have ever seen is part of it. ... There is nothing so far away from us as not to be part of our world. Anything at any distance at all is to be included. Likewise the world is inclusive in time. No ... long-gone primordial clouds of plasma are too far in the past, nor are the dead dark stars too far in the future, to be part of

\footnotetext{
11 One could read John McTaggart's (1908) famous conclusion that time is 'unreal' as based on an argument to the effect that there is no satisfactory way to tie the original temporal nexus to an underlying atemporal reality. For critical discussion of the separation between the conceptual and the real that the reductionist assumes, see Ellis (2005) and Mulder (2012, 2014).
} 
this same world. ... [N]othing is so alien in kind as not to be part of our world, provided only that it does exist at some distance and direction from here, or at some time before or after or simultaneous with now. (Lewis 1986, p. 2; my emphasis)

Lewis here displays the most straightforward implementation of the reductive approach: take the atemporal, geometrical order of space, and append time as another, similar dimension to that order. Varieties of the resulting 'fourdimensionalism' are widely endorsed amongst contemporary analytic metaphysicians. $^{12}$

The result of this procedure is a view on time that rests exclusively on the atemporal form of predication we contrasted the original temporal nexus with in the previous section - as I will now show by briefly explaining how this approach gives rise to the three views that I am mostly concerned with in this paper: eternalism, B-theory, and perdurantism.

Recall geometrical figures on the Euclidean plane: the plane as a whole provides the locations for such figures - it is the big two-dimensional container that [contains] all of them (as before, [square brackets] indicate Frege's atemporal form of predication). Similarly, on the view under consideration, reality is to be thought of as providing 'spatiotemporal' locations for its inhabitant objects-it is the big four-dimensional container that [contains] all of them. Thus, we have eternalism: everything past, present and future [belongs] to reality as a whole.

The typical form temporal statements then take involves a specification of the relevant temporal location(s) - either absolutely ("the glass [is] on the table on 2016-6-17, 11:29:41") or relationally ("the glass [is] on the table before it [is] in the kitchen"). In both cases, the temporality consists in such location-specification, the form of predication used is thus atemporal. In other words, we have B-theory: temporal truths are tenseless (or are grounded in truths that are tenseless).

Interestingly, it is only temporal location-specification that comes with such atemporality-whether or not something is before or after something else doesn't change. Spatial location-specifications are subject to change, of course, and hence require the temporal form of predication (unless we start conceiving of such objects as having temporal parts-which is the view we now turn to).

Just as a geometrical figure can be understood to occupy an extended region of the Euclidean plane by having, for each subregion of that extended region, a part (ultimately, points) occupying that subregion, physical objects on this orthodox four-dimensionalist view occupy their entire four-dimensional location by having, for each subregion of that location, a part (ultimately, mereological atoms) occupying just that subregion. In other words, we have perdurantism: things persist by having temporal parts at every time at which they exist. ${ }^{13}$ This allows for a

\footnotetext{
12 See, e.g., Quine (1960); Lewis (1986, 1991); Hawley (2002); Sider (2001, 2012); Chalmers (2012); Williamson (2013). Most of these urge that the temporal dimension is not the same as the spatial dimensions - but often don't have convincing means to say wherein the difference then lies. E.g., Sider (2001, p. 216) suggests that the difference 'might even be primitive'.

13 Here I ignore several complications and subtleties, such as the possibility of gunk without mereological atoms, the possibility of temporally extended mereological atoms (which would not persist
} 
treatment of temporal truth completely analogous to 'locational' truth: "the poker [is] hot at time $t$ " and "the poker [is] hot at location $l$ " are both true (supposing that they indeed are) because the poker has a part at the relevant location ( $t$ resp. $l$ ) that is hot.

On this threefold basis, of eternalism, B-theory, and perdurantism, the reductionist may proceed to capture further features of the original temporal nexus. With regard to tense, for instance, there are various options. Traditionally, it has been held that tensed statements are to be understood as tenseless statements involving a kind of self-reflexive element. ${ }^{14}$ So-called 'new' B-theorists reject such an eliminative reduction; they want to keep tense on board as a genuine conceptual ingredient of temporal thought, but without claiming that reality itself is somehow tensed: our temporal thoughts are then taken to be irreducibly tensed, without this implying that a B-theoretic account of their truthmakers (or grounds) is false or incomplete. $^{15}$ Aspect is more difficult to construct satisfactorily: the idea of temporal locations (or of temporal extension) does not help to distinguish processes that reach their completion from those that do not. However, aspect is mostly ignored or overlooked in the debate anyway. ${ }^{16}$ Perhaps a subjectivist/pragmatic approach in terms of expected outcomes of events that may or may not correspond with their actual future continuation will do (I will leave the details to those concerned with developing the reductive view).

There is considerable debate on all three mentioned dimensions of the reductive view. Apart from quarrels amongst proponents of the reductive view itself (such as exdurantism vs. perdurantism), there is a persistent minority opposing some or all of the three, and defending presentism, A-theory and/or endurantism instead. One might assume, now, that these opposing views form part of the original view. However, I challenge that assumption. The original view is indeed inconsistent with

\section{Footnote 13 continued}

by having temporal parts, but still occupy their spatiotemporal region), and the possibility of identifying the objects with their spatiotemporal regions. Notice, though, that such an identification comes natural to those attracted to four-dimensionalism. Sider (2001, p. 110), for instance, writes that " $[\mathrm{t}]$ he identification of spatiotemporal objects with the regions is just crying out to be made." Compare, again, geometry: a triangle on the Euclidean plane is naturally thought of as identical with the region its constituent lines (or points) occupy on the plane itself. In other words: it is just part of the plane.

14 On such a construction, your statement "I am reading now", for instance, is true just if the reported event of reading [is] simultaneous with the statement itself. This 'token-reflexive' reduction of tense to B-relations has been defended, e.g., by Russell (1919, 1941), Reichenbach (1947, §§50-51), Williams (1951, p. 463), Ayer (1956, pp. 152-153), and Smart (1963, pp. 132-142).

15 See, e.g., Lewis (1979), Oaklander (1991), Oaklander and Smith (1994), Mellor (1998). Zimmerman (2005) uses this kind of view for his argument that A-theory has to involve more than just 'taking tense seriously'. This change in the B-theorist's strategy illustrates the broader movement from philosophy of language to metaphysics. Whereas earlier the issue between A-theory and B-theory concerned the question whether or not the tenses could be analyzed away from our language, now the issue is taken to concern whether or not the tenses play any role in the truth-makers for our (perhaps irreducibly tensed) true thoughts and utterances.

16 But see Boccardi $(2015, \S 4)$, who admittedly doesn't mention aspect but does argue that genuine dynamicity in one's account of time requires obedience to what he calls 'Plato's Principle': "nothing can undergo a (comparative) change [perfective aspect] if it is never found in a state of changing [progressive aspect] before the change has been produced". 
eternalism, B-theory and perdurantism, for the simple reason that these views are built on atemporal predication, not on the temporal form of predication that constitutes the core of the original view. But that doesn't imply that presentism, A-theory and endurantism are parts of the original view. For, as we will see, all three of these views, both when taken separately and when taken together, can be understood in such a way as to not involve temporal predication but rather the reductionist's atemporal form of predication - albeit in much less obvious ways. Such reductive versions of presentism, A-theory and endurantism are, in effect, 'unorthodox' forms of the reductive approach whose 'orthodox' form I just sketched. Yet it seems that the motivation for such unorthodox views derives from a dissatisfaction with the way in which reductionism reduces time to merely another dimension, grounds tensed truths in tenseless truths, and reduces persistence to mere concatenations of temporal parts. That reductive picture provides, in the eyes of the opposing minority, an unsatisfactory view on reality as a four-dimensional, completely static 'block universe'.

Given these observations, we would do well to recalibrate the discussion on time so as to better track the reductionism/anti-reductionism opposition. In order to make my case for this conclusion, I consider all three of the mentioned debates in a bit more detail. I start with a discussion of persistence in Sect. 4. I show that at least some respectable versions of endurantism amount to mere variations on a reductive understanding of persistence. The only version of endurantism which promises to yield a genuine alternative to perdurantism is a version that combines endurantism with A-theory, and therefore I move on to discuss A-theory in Sect. 5. As it turns out, A-theory, at least on some respectable versions of that view, rests upon a reductive understanding of tense. The only version of A-theory which promises to yield a genuine alternative to B-theory is a version that combines A-theory with presentism, and therefore I move on to discuss presentism in Sect. 6. Now, even here, it turns out that presentism can easily be understood in such a way as to incorporate the very same reductive notion of being temporally located that was troubling A-theory.

Having thus assimilated all of the seemingly opposing views into the reductive view itself, the question remains what, then, the corresponding components of the original view are. In some sense, endurantism, A-theory and presentism do form part of the original view, but only when developed on the basis of its defining, temporal form of predication-not on the basis of some (perhaps tacitly) assumed common ground with the reductionist. Within the original view, there is no conceptual room for such common ground, no room for mapping the apparent oppositions perdurantism/endurantism, B-theory/A-theory and eternalism/presentism. Hence my conclusion: at bottom, the issue is whether or not reduction is possible. All else is mere quarrels within the reductionist's camp. I end this paper by briefly remarking on the way in which the original view does incorporate endurantism, A-theory and presentism in Sect. 7. 


\section{Persistence}

Endurantism and perdurantism are competing views on persistence. Enduring objects "sweep through" their life-time, perduring objects are "spread out" over their life-time; endurantists hold that persisting objects do so by being wholly present at each time at which they exist, while perdurantists hold that persisting objects do so by being partly present at each time at which they exist. Those are the typical slogans. ${ }^{17}$ I will now introduce a rather unorthodox way of arriving at certain versions of these two competing views that makes clear their shared reductive background. $^{18}$

Consider a simple temporal statement: " $a$ is $F$ ". A B-theoretic, reductive rendering of that statement is: " $a$ [is] $F$ at $t$ " -the temporal form of predication gets replaces by the atemporal form, and instead a temporal reference makes its appearance. The intuitive thought behind this move is as follows: at a certain position on the time line, $t$, it holds that $a$ [is] $F$. However, the resulting statement shows that that intuitive thought is not as clear as it seems. For that statement has the (Fregean) form of a two-place relational predication: $F$ suddenly no longer stands for a property of $a$, instead, it relates $a$ and $t$. It seems that something got lost in this translation. ${ }^{19}$

One can dismiss this worry, and hold that all temporal predications indeed involve such a (perhaps hidden) extra argument place for times. This leads to a position on persistence that I call time-relative endurantism. But one can also try to resolve the worry by somehow eliminating the temporal reference. There appear to be two options: building the temporal reference into the object (yielding $a_{t}$ [is] $F$ ), and building the temporal reference into the predicate (yielding $a$ [is] $F_{t}$ ). The first option results in perdurantism, the second in what one could call property-based endurantism. Property-based endurantism is, arguably, no more than a variant of time-relative endurantism, and therefore I will not discuss it separately in what follows. $^{20}$

\footnotetext{
17 To separate the two views on the basis of acceptance or rejection of temporal parts in this way is not entirely adequate. As Katherine Hawley observed (2002, §1.6), endurantists may in principle accept temporal parts on top of enduring things, and perdurantists may in principle even reject temporal parts in favor of temporally extended but (mereologically) atomic perduring things. Her alternative criterion is in terms of acceptance or rejection of an atemporal notion of parthood: perdurantists accept that things can have parts simpliciter while endurantists insist that, for persisting things, parthood is always time-relative. This nuance, however, does not make much difference to my considerations below.

18 I take my cue here from Rödl ( 2012, ch. 3, §2).

19 This is the basis for Lewis's famous 'argument from temporary intrinsics' against the endurantist-see his (1986, esp. pp. 202-204) and (2002). The literature on this argument can be misleading, because intrinsics aren't really the issue. See Eddon (2010), who shows that the argument rests on the claim that the endurantist must say that the fundamental features of persisting things (intrinsic or not) are all relations involving times.

${ }^{20}$ Endurantist views of the time-relative variety have been defended by Mellor (1981, ch. 7) and van Inwagen (1990), and are considered in a sympathetic manner by Rychter (2008), Eddon (2010). Though we should note that Mellor abandoned the view, in later work, because it seemed to him to allow things having properties relative to times at which they do not exist. See Mellor (1998, ch. 8). I should mention a third option-building the temporal reference into the copula: $a$ [is $]_{t} F$. This 'adverbialist' proposal has been offered by Johnston (1987), Lowe (1987, 1988), Haslanger (1989). However, it is unclear whether
} 
As my presentation suggests, these three views on persistence can be taken as alternative ways of endorsing B-theory. As such, they share a common reductive background picture of temporality: temporal thoughts are understood in terms of the atemporal form of predication. Therefore, the objects that figure in such temporal thoughts fall under Frege's category of Gegenstände, not under the category of substances pertaining to the temporal form of predication. (Recall that categories are defined by reference to the form of predication to which they belong.) As such, we should expect to find that all such objects are exhaustively described by an (infinite) set of atemporal truths-just like a number, say, can be so described. ${ }^{21}$ And that is indeed what we find.

For the perdurantist, the relevant objects are all the momentary time-slices (temporally extended composite things derive their temporal properties from their constitutive time slices). Each of them comes with its own set of truths regarding its properties, and these truths are all atemporal truths having forms like " $a_{t}$ [is] $F$ ". They can be said to exist in time by being located at some specific point on the time line.

For time-relative endurantism, the basic temporal objects are neither time slices nor temporally extended things, but something more abstract altogether. As Rychter writes regarding a ripening banana from a time-relative endurantist point of view:

[A]n atemporal perspective will show the banana somehow outside time, and bearing different relations to different times. These are the relations in virtue of which, from a temporal perspective, the banana has different colors at different times. (Rychter 2008, p. 165)

Here, the 'atemporal perspective' is the metaphysically fundamental one, it is the one by virtue of which there is a 'temporal perspective' in the first place. From the atemporal perspective, they are 'outside of time' in the sense that that perspective shows, in good reductionist fashion, by virtue of what they are 'in time'. As in the case of the perdurantist's time-slices, then, every temporal object comes with its own set of truths regarding its properties at various times, and these truths are all atemporal truths having forms like " $a$ [is] $F$ at $t$ ".

Endurantism, when understood along the sketched lines, is a reductive view on persistence. Like perdurantism, which reduces persistence to series of time slices, it reduces persistence to series of relations to times. In this guise, the perdurantism/ endurantism debate is a debate that is internal to the reductive perspective: it is a debate about which construal of B-theory is to be preferred.

Footnote 20 continued

this proposal is just a roundabout way of reintroducing the temporal form of predication (that is, it is unclear whether "[is $]_{t}$ " = "is"). Anyway, adverbialism usually comes with A-theory, whereas I here consider endurantism apart from that further commitment. For critical discussion of the adverbialist view, see, e.g., Hawley $(2002, \S 1.5)$.

21 By contrast, of substances, things to which the temporal form of predication applies, the history up until now can be exhaustively described by an (infinite) set of temporal truths. There is no atemporal perspective from which to describe substances. 
Or is this conclusion too fast? After all, there are those who defend endurantism by rejecting B-theory. ${ }^{22}$ Interestingly, one can find writers in the persistence debate insisting that such a move amounts to withdrawing from the debate over persistence altogether. For example, here is Hawley insisting that the basis for the debate is the acceptability of 'atemporal talk':

Both endurance and perdurance theorists will accept that the yellow banana used to be the green banana, although the theories can give different atemporal descriptions of the underlying reality so long as atemporal talk is permitted. ... If we are only permitted to talk about how things are [now], then the most we can do in speaking of persistence is to speak of the histories and futures of objects .... We cannot assert or deny claims of identity between objects existing at different times, and thus endurance theory is unformulable. (Hawley 2002, pp. 31-32)

Hawley claims that rival theories of persistence offer 'different atemporal descriptions of the underlying reality': she thus makes clear that she demands the participants in the debate over persistence to adopt a reductive stance (in my sense). In response to those insisting on an A-theory-based version of endurantism, she writes:

Those who adopt an irreducibly tensed view of the temporal world, and do not accept that a tenseless description can ever be even partially adequate need have no truck with the debate between endurance and perdurance theories. (Hawley 2002, p. 34)

If Hawley is right, the notion of endurance cannot be used to develop a position that opposes the reductive view. Unless, of course, we can provide it with a content that differs from what we have seen so far: with content that does not depend on the reductive stance. The only suggestion we now have in that direction is to start with A-theory. Let us see how A-theory fares.

\section{Tense}

The basic thought of A-theory is that tense plays a fundamental role in the constitution of temporal reality. Thus, although B-theoretical rephrasings of tensed truths are not by themselves objectionable, the B-theoretical claim that such rephrasings are, metaphysically speaking, the basis for temporal reality, is objectionable.

Arguably, the best-known versions of A-theory combine A-theory with presentism. ${ }^{23}$ However, as with my discussion of endurantism above, I here choose to introduce A-theory in an atypical way, in order to show in what guises it comes

\footnotetext{
22 See, for instance, Merricks (1994, 2007), Zimmerman (1998).

23 See, for instance, Prior (1957, 1967), Geach (1966), Chisholm (1990a, b), McCall (1994), Lowe (1998, ch. 4), Merricks (1999, 2007), Hinchliff (2000), Crisp (2004), Markosian (2004, 2013), and Zimmerman (2005, 2008).
} 
down to being reductive in nature. Whether the addition of presentism makes a difference will be my topic in the next section-but, given the close connections between A-theory and presentism, my treatment of them cannot be fully separate: I postpone some of the considerations relevant to A-theory until the next section (in particular, concerning Prior's tense-logical understanding of tense, since that will take us to the heart of the reductive view), and I will include some considerations here that already involve presentism (in particular, concerning Prior's presentist conception of passage).

The eternalist says that everything past, present, and future is part of the big fourdimensional container that is reality. It is natural, then, to adopt a B-theoretic rendering of temporal facts: they are temporal not by form, for they involve the atemporal form of predication, but by being located somewhere or other in the big four-dimensional container. That location is specified in some way or other in their contents. I will now show that it is equally possible, although more complicated, to adopt an A-theoretic rendering of such facts: such an A-theory will then be a reductive A-theory.

A useful starting point is Kit Fine's intriguing paper on the reality of tense, in which he explicitly separates his topic from ('ontic') presentism:

Ontic presentism is an ontological position; it is a view about what there is. [A-theory], ${ }^{24}$ on the other hand, is a metaphysical rather than an ontological position; it is a view about how things are, quite apart from what there is. ... Moreover, ontic presentism is a negative view; it excludes certain things from what there is. [A-theory], on the other hand, is a positive view; it includes certain ways of being in how things are. ... It is readily possible for [an A-theorist] not to be an ontic presentist. ... He merely insists that some of the facts (if not all) should concern how things presently are. (Fine 2005b, pp. 299-300; terminologically adapted)

From this starting point, Fine develops and discusses three distinct versions of A-theory, that I will use as examples of non-obviously reductive A-theories. Fine takes tensed facts to have forms like " $a$ is $F$ ", "it was the case that $a$ is $F$ ", "it will be the case that $a$ is $F$ ", etc. That is, he takes them to have the forms that Arthur Prior captured in his famous tense logic: $p, \mathbf{P} p, \mathbf{F} p$, etc. ${ }^{25}$ These are the kinds of 'perspectival' facts that B-theorists would take to be grounded in atemporal facts of the form " $a$ [is] $F$ at $t$ ". B-theory thus resolves the perspectival character of such tensed facts. On the first version of A-theory Fine discusses, standard A-theory, the perspectival character is retained: standard A-theory presupposes that the present moment is privileged. (It is easy to see that this version of A-theory makes for a good match with presentism.)

\footnotetext{
${ }^{24}$ Fine talks about '(tense-theoretic) realism' instead of 'A-theory'. For clarity, I will continue to speak of A-theory, and adapt Fine's terminology accordingly, using [square brackets] to indicate such replacements in quotes from his paper.

${ }^{25}$ See, e.g., Prior (1957, 1967, 1968b), and of course Prior's posthumously published collection of essays entitled Worlds, Times and Selves, which Fine put together and wrote an extensive postscript for (Prior and Fine 1977).
} 
In addition, Fine describes 'non-standard' versions of A-theory, on which there is no such privileging of a particular moment. On such a view, not only the tensed facts of the present moment are included in reality, but also the tensed facts of all other moments. On Fine's understanding of what it is for tensed facts to belong to reality, this creates a problem of anchoring: which tensed fact belongs to which moment? Moreover, without such anchoring, a problem of coherence arises as well: " $a$ is $F$ " and " $a$ is not $F$ " may both belong to reality, despite contradicting each other. There are two options for dealing with these problems, yielding two versions of non-standard A-theory: external relativism and fragmentalism. According to the external relativist, there are at bottom many realities, corresponding to moments in time, each with its own collection of tensed facts. ${ }^{26}$ According to the fragmentalist, there is one 'über-reality', which is incoherent, and decomposes into coherent fragments (that roughly correspond to the relativist's many realities). ${ }^{27}$

Some observations are in order. First, what the standard A-theorist takes to be the whole of reality - all the tensed facts about past, present, and future-is just one of the many realities (fragments) for the relativist (fragmentalist). Secondly, and relatedly, the non-standard A-theories incorporate a massive multiplication of what appear to be the very same facts. Consider: amongst yesterdays's facts there is the fact that it $i s$ (at that time) raining. Amongst today's facts there is the fact that it was raining. These are the very same fact (as I noted already in Sect. 2 above, and will illustrate further below), yet for the non-standard realists, they are not-they don't even belong to the same reality (and are likely not always in the same fragment). And thirdly, this, in turn, raises the question why we should assume the many realities (or fragments) to mesh in the natural way: if today's collection of tensed facts (about past, present, and future) is entirely disjoint from tomorrow's collection of tensed facts, it seems perfectly fine for today's reality to contain the fact that it raining while tomorrow's reality contains the fact that it was not raining. ${ }^{28}$

Fine does not address this last issue. It is perhaps natural to appeal to the axioms of Prior's tense logic in order to deal with them, such as $p \rightarrow \mathbf{F P} p$. However, these principles apply only within each of the many realities (or fragments). They don't help for our 'cross-reality' (or 'cross-fragment') worries.

That such worries arise is a clear sign that something has gone wrong. What has disappeared from sight is the dynamic unity of temporal facts: their cross-temporal

\footnotetext{
${ }^{26}$ External relativism contrasts with internal relativism. B-theory can be considered a version of internal relativism: which tensed facts hold is relative to the moments on the time line. Such a relativism is internal because it is explained by reference to an underlying absolute stratum of (in this case tenseless) facts. The external relativist rejects such an underlying absolute reality.

27 I say "roughly", because for the fragmentalist, the fragments need not correspond to times. The fragments may overlap, and they may contain tensed facts belonging to different times. For Fine, this is a reason to prefer fragmentalism: it makes sense from a relativistic point of view, since it does not rely on a notion of absolute simultaneity.

28 A further observation: the standard A-theorist can allow for the future to be open (in the sense that there simply are no future-tensed contingent facts), while the non-standard A-theorist can only allow for such openness in a very peculiar way-the relativist, say, can hold that relative to today's reality it is indeterminate whether or not there will be a sea battle tomorrow, while relative to tomorrow's reality the fact holds that there is a sea battle going on. Such 'relative openness' is not likely what defenders of an open future are looking for (although Pooley (2013, §VI) seems to think otherwise).
} 
sameness. That is the result of the shortcoming in Prior's tense-logical understanding of temporal truths I have just indicated. I will come back to this in the next section; first, we should look into a more general worry of dynamicity: the famous (and notorious) idea that time passes. ${ }^{29}$

Fine uses the idea of passage in one of his arguments in favor of non-standard A-theory. To that effect, he critically reflects on standard A-theory as follows:

[G]iven a complete tenseless description of reality, then what does [the standard A-theorist] need to add to the description to render it complete by his own lights? The answer is that he need add nothing beyond the fact that a given time $t$ is present .... But then how could this solitary 'dynamic' fact ... be sufficient to account for the passage of time? ... [H] is conception of temporal reality, once it is seen for what it is, is as static or block-like as the [Btheorist]'s, the only difference lying in the fact that his block has a privileged centre. Even if presentness is allowed to shed its light upon the world, there is nothing in his metaphysics to prevent that light being 'frozen' on a particular moment of time. (Fine 2005b, pp. 286-287)

It becomes evident, at this point, that the version of standard A-theory Fine here considers comes down to what is often called moving spotlight theory. ${ }^{30}$ Its moving spotlight is supposed to account for the passage of time-but, as Fine rightly remarks, adding tensed facts only provides the spotlight theorist with a spotlight, not with its movement.

What is remarkable about this form of A-theory is that it first accepts an eternalist construal of how truths relate to times, and then seeks to rescue the cherished dynamicity of time by adding tensed facts. The situation is similar to that in the case of the endurantisms I surveyed above: there, we noticed that they first adopt a B-theoretic/eternalist understanding of temporal truth, and then seek to rescue the diachronic identity of persisting things.

The question Fine poses is, thus, indeed an important one for the moving spotlight theorist: he may say that the tensed fact he adds to the tenseless description is 'dynamic', i.e., that the spotlight 'moves', but the tensedness of the fact itself does not seem to do the trick (which, to repeat, indicates that there is something peculiar about the kind of tensedness involved). Moreover, given this predicament, it is clear that replacing all the B-theoretic facts by tensed facts does not make much difference either. ${ }^{31}$

\footnotetext{
29 I should warn the interested reader at this point: I will not be able to provide a satisfactorily developed account of the passage of time in this paper. That is not my aim in this paper; I' $m$ in the end merely using the idea of passage to clarify differences between a reductive and non-reductive approach to time.

30 For C.D. Broad's original image of the moving spotlight view, see Broad (1923, p. 59). Defenders of something like the moving spotlight theory include Russell (1915), Smith (1993, 2002), Craig (2000). Moreover, Skow (2009) attempts to make moving spotlight theory compatible with special relativity.

31 In fact, the whole idea of a moving spotlight is deeply confused: it tacitly introduces an extra temporal dimension, in which the spotlight moves, which exists apart from the time line itself. (Broad 1923, p. 60) already observed this; see also (Williams 1951, pp. 463-464), and Markosian (1993) for a more recent discussion of this argument. Skow (2009) argues that the alleged extra temporal dimension can be cashed out in terms of tensed truths concerning the 'real' time line-but see Pooley (2013, §IV) for convincing
} 
Interestingly, Fine takes the non-standard A-theories to fare better in this respect:

For the external relativist, each time is objectively present at that time: at each time $t$, reality is constituted by the absolute fact that $t$ is present .... And for the fragmentalist, each time $\mathrm{t}$ is objectively present simpliciter-i.e., reality is constituted by the absolute fact that $\mathrm{t}$ is present .... But in either case, presentness, in so far as it is a genuine feature of reality, applies equally to all times. Presentness is not frozen on a particular moment of time and the light it sheds is spread equitably throughout all time. (Fine 2005b, pp. 287-288)

Fine of course knows that such an equal distribution of presentness over all times does not suffice as an adequate account of the passage of time, but he nevertheless takes it to be an improvement in comparison to the situation of the standard A-theorist:

[A]t least, on the current view, there is no obvious impediment to accounting for the passage of time in terms of a successive now. We have assembled all the relevant Nows, so to speak, even if there remains some question as to why the relationship between them should be taken to constitute a genuine form of succession. (Fine 2005b, p. 288)

Fine's line of thought here is not convincing. For consider: the moving spotlight theorist may have a problem of 'frozenness', but, at least, there is room for the spotlight to move in. Non-standard A-theorists make things worse by incorporating the presentness of every moment into the moment itself: now there is no room anymore for the spotlight to move in. Its beam is widened so as to illuminate all times 'at once' — but it is just as 'frozen' as the original spotlight (pace Fine's claim to the contrary). Indeed, adding presentness to each moment sounds very much like B-theory, where each moment is, likewise, present (though only relative to itself, instead of absolute).

Recently, Oliver Pooley defended standard A-theory against Fine's charge that its present moment remains 'frozen', with the help of Prior's account of presentist passage. Change consists, on Prior's tense-logical understanding (on which more below), in the truth of tensed conjunctions like " $b$ was $G$ and $b$ is not $G$ ". Since, e.g., "Prior's birth was 54 years ago, and his birth is now not 54 years ago" has the very same form, it is also an instance of Priorian change-and Prior writes, with regard to such a peculiar change:

This last change, of course, is a case of precisely that recession of events into the past that we are really talking about when we say that time flows or passes .... (Prior 1968a, p. 9)

Thus, Pooley says, if we adopt Prior's tense-logical understanding of change, we inherit a perfectly fine conception of the passage of time. He writes:

Footnote 31 continued

criticism, leading to the conclusion that the moving spotlight view endorses an eternalist take on ordinary time and a presentist take on the extra temporal dimension that underlies the movement of the spotlight. 
The present, tensed facts include, for example, facts to the effect that certain tensed propositions are not now true but that they were or will be true. One simply cannot accept all the present, tensed truths without accepting that what is true undergoes genuine change. (Pooley 2013, p. 330)

Pooley here seems to gesture towards an aspect of the original temporal nexus that Fine failed to take into account: it lies in the very form of temporal truths that they "recede into the past". In other words, there are no tensed truths without passage. (That is, in fact, the only way to arrive at a satisfactory non-reductive understanding of the passage of time. I will come back to this thought in Sect. 7 below.) Notice, however, that on Pooley's way of putting things, this thought cannot be maintained. For the thought that some tensed propositions "are not now true but were or will be true" is itself simply a present-tensed proposition, located at the present moment, and therefore suffers from the very same lack of cross-temporal integration of temporal facts that I pointed out earlier. For all Pooley and Fine have told us, there is no link whatsoever between today's fact that "proposition $p$ was true yesterday" and yesterday's fact that "proposition $p$ is true today". And without such a link, there is nothing in today's tensed facts that secures that "what is true undergoes genuine change". But, again, I will return to this point in the next section; I will now conclude this section by showing that Pooley's understanding of temporal passage suffers from a different (but related) flaw.

The way Pooley extends the understanding of passage he finds in Prior to Fine's non-standard A-theories shows that there is something strange going on:

Do non-standard views vindicate the passage of time? The first, obvious point to make is that everything the presentist said was true absolutely remains true relative to a particular temporal perspective. And everything the presentist maintained was always true remains true relative to every temporal perspective. Since time passes for the presentist, the same holds true, as of any time, of the non-standard view. One of the view's many perspectives is supposed to be our perspective so we can truly say (now) that time passes. (Pooley 2013, p. 335; emphasis added)

This line of thought is flawed. In so far as Prior's presentist, tense-based understanding of time's passage is successful, it yields passage of time for the presentist's reality. Now, the one single reality of the presentist A-theorist is identical to one of the many realities (or fragments) of the non-standard A-theorist. However, contrary to what Pooley thinks, the imagined generalization of Prior's account then yields as many 'moving nows' as there are relative realities (or fragments). ${ }^{32}$ By marrying the Priorian idea of understanding passage in terms tense itself with the idea of a multitude of temporal locations (i.e., realities or fragments),

\footnotetext{
32 The point becomes especially vivid when considering the open future, for then what is taken to be genuinely open relative to the present reality (say, whether or not there will be a sea battle tomorrow) is not open relative to some future reality (in which a sea battle is raging, let us say). That seriously compromises the sense in which the future is 'open'.
} 
Pooley ends up with a host of different 'passages': a different 'moving now' for each moment. That, however, makes nonsense of the very idea of time's passage. ${ }^{33}$ One might think that this problem may also be blamed on the non-standard realisms, instead of blaming it on Pooley's understanding of passage. However, things are more complicated: the extension to non-standard A-theories shows that the view of passage in question is compatible with the idea of anchoring tensed facts to locations on (a relativist/fragmentalist substitute for) the time line. And it is that anchoring which creates the problem.

To sum up: there is a way of understanding the relation between tensed truths and their respective moments that is just like the B-theoretic understanding of how tenseless truths relate to their respective moments. The only difference is that for the B-theorist the relevant temporal locations are built into the truths themselves, whereas the A-theorist has to anchor them in some other way (by privileging the present moment, or by endorsing a relativization or fragmentation of reality). Such an understanding of tensed truths is as reductive as B-theory. In short, it matters a great deal how one understands tense.

Perhaps presentism can enforce an understanding of tense that is not in line with the B-theorist's take on temporal location, simply because it denies the existence of any temporal locations except for the present moment.

\section{Presentism}

As before, I will focus here on versions of presentism that are fully compatible with the reductive view. It is, in fact, easy to construct a version of presentism that is just an alternative to 'orthodox' eternalism, acceptable in principle to reductionists (though most likely not preferable):

$[\mathrm{C}]$ onsider a view that starts with the eternalist's picture of time and existence at a time, and then 'shaves off' the past and the future, leaving only a thin (instantaneous?) slice called 'the present'. (Merricks 2007, p. 124)

Let us call this version of presentism negative presentism. ${ }^{34}$

I introduce it here because it is built not on a rejection of the eternalist understanding of time but rather accepts it, as I will explain shortly. The negative presentist's reality collapses into one static snap-shot, and thus, as we should expect, time's passage remains a mystery, for nothing in this picture ensures that reality, confined as it is to just one moment, changes. This is the counterpart, for negative presentism, of the 'frozenness' of the spotlight we observed, with Fine, in the previous section. (I return to the promising tense-based Priorian notion of passage that Pooley called to his aid in the next section.)

\footnotetext{
33 In a recent paper that does not consider Fine's or Pooley's positions, Boccardi $(2015, \S 5)$ asks "if at all times presentness advances not at all, isn't it miraculous that in a series of such static moments it manages to advance?"

34 I take this label, indirectly, from Fine: see the quote I presented at the beginning of the previous section.
} 
Negative presentism helps us to pin down what it is about the eternalist picture of a time line that makes it a reductive picture. It makes clear that the foundation of the reductive view is not the extendedness of its eternalist time line. Rather, it is its very understanding of what it is for something (be it an object, fact, truth, state of affairs or something else) to exist at (hold at, be true of) some time or other. ${ }^{35}$ That understanding is atemporal: time is supposed to be accounted for, reductively, by the time line itself. Every moment in time comes with its own collection of objects and/or truths; it is the relation amongst moments (in particular, their linear ordering) that constitutes the basis for the reductionist's understanding of time.

The moments are, thus, construed rather like instantaneous possible worlds, ordered in a 'temporal' series. But such instantaneous 'worlds' are atemporal (recall the Euclidean plane from Sect. 2). Time is reductively conceived of as a series of atemporal instants - just as modality may be reductively conceived of in terms of a range of a-modal possible worlds. The Humeanism in both conceptions is obvious: all the instants (or worlds) are, at bottom, 'loose and separate'; they can be exhaustively described without reference to other instants (or worlds), using atemporal predication only.

To describe what reality is like at one particular instant, it is natural to use atemporal predication: time comes in only as one considers that instant in its relations to other instants on the time line. This is the reason why an alternative rendering of such B-theoretic facts as 'tensed' ones is of little help: if the underlying understanding of how such facts relate to the time line remains the same, their 'tensedness' makes little difference-as my discussion of Fine's versions of A-theory in the previous section illustrated. Indeed, I will now show that this way of understanding tense is reductive-which is to say that the basic, present-tensed facts populating all the separate instants in fact involve the atemporal form of predication, not the temporal form.

For concreteness, I consider an example: Bourne's 'ersatzist' version of negative presentism. He writes:

I propose we construct times using maximally consistent sets of $u$-propositions, ${ }^{36}$ which intuitively we can see as those $u$-propositions that are true at that time. These propositions I take to give a complete, maximally specific, description of what is true at that time. ... [These times] need to be ordered by an 'earlier than' relation ..., in order for the ersatz time series to be structurally similar to a real time series, so it can be taken to be a sufficient substitute. (Bourne 2006, pp. 53-54)

Bourne thus replaces the eternalist's 'real' time line with an ersatzist time line. One point on this substitute time line is occupied by reality: the present moment. The

\footnotetext{
35 Merricks makes the same observation (2007, p. 124). The mistake, he thinks, lies in the assumption that presentism and eternalism 'agree about what it is to exist (and have properties) at the present time' [p. 123]. I agree with this diagnosis - but not with Merricks's positive view on temporal truth (see below). See also Tallant $(2014, \S 3)$, who adopts Merricks suggestion in developing his 'Existence Presentism', according to which presence simply is existence.

36 Bourne defines ' $u$-propositions' to be atomic, present-tensed propositions.
} 
earlier-later relation that holds between all the times grounds the various past and future truths at the various moments. ${ }^{37}$

Bourne reconstructs the eternalist's reductive view on time by simulating the very time line he does not want to countenance, as a presentist. Why? Because he still holds on to the eternalist's understanding of temporal truth, in terms of locations on a time line. ${ }^{38}$ Given this eternalism-friendly understanding of temporal truth, there appears to be no difference at all between the negative presentist's reality and a temporally thin eternalist reality.

For consider: the negative presentist's time line shrinks to the size of one single moment. He alleges this moment to be characterized by present-tensed truths (Bourne's $u$-propositions). An eternalist, B-theoretic but temporally thin reality would incorporate atemporal truths concerning the only 'moment' that exists. So why should we think that Bourne's basic, allegedly present-tensed $u$-propositions are any different from our imagined eternalist's basic, atemporal propositions?

We should return, here, to the observation I made in the previous section concerning Prior's tense logic: it seems to capture only the interrelations between tensed statements from one and the same temporal perspective, but it doesn't capture their dynamicity, their cross-temporal sameness. That is, Prior is expressing something that goes beyond his own logic when he writes:

In tense logic the totalities of tensed propositions which are true at different instants fit together into a system, so that although the total course of history will be differently described at different times, the description at one time will determine what the descriptions at other times will be. (Prior and Fine 1977, p. 38)

As Rödl observes, considering an intellect that would only think thoughts of the forms that tense logic describes:

Such an intellect is a totality of tense-logical contents, wherefore the system of these totalities is not accessible to him. One instance follows the other, and with it one totality takes the place of the previous one. ... The meaning of a tense-logical sentence resides in the conditions under which "is-present true" applies to it, and these are different at different times. Hence, as time passes, the meaning of all tense-logical sentences shifts. ... Since the meaning of all of his sentences shifts, he has no means to say that it shifts. (Rödl 2012, p. 106)

\footnotetext{
37 A similar presentist view has been defended by Crisp (2007).

38 Another, more proximate reason for Bourne to proceed as he does is the famous truthmaker argument against presentism: if only present things exist, then what 'makes true' statements like "There were dinosaurs" and "I admire Aristotle's wit"? This argument, and similar ones, are presently widely discussed-see, e.g., Prior (1968a), De Clerq (2006), Fiocco (2007), Caplan and Sanson (2011), Baia (2012), Baron (2012, 2013), Torrengo (2013, 2014), Asay and Baron (2014); Tallant (2014). Merricks (2007, esp. ch. 6) contains a critical discussion that is particularly congenial to my project here. In terms of the classification proposed by Sam Baron in a recent contribution (Baron 2015), Bourne's account is a form of 'easy road' presentism: invoking new entities that can act as truthmakers. Baron himself develops 'middle road' presentism, providing tensed truthmakers. Merricks defends what Baron calls 'hard road' presentism: he rejects truthmaker theory, writing that 'no possible view can reconcile presentism with Truthmaker' (Merricks 2007, p. 138).
} 
Leaving the tense-logical intellect aside, we may say that a tense-logical reality is a totality of tense-logical facts (Fine's versions of A-theory being our primary examples). Then, that yesterday's $p$ is the same as today's $\mathbf{P} p$ is something that cannot be included in reality as an extra tense-logical fact: firstly because it will then itself stand in need of being put into the system by way of further facts of crosstemporal fact-sameness, leading to a regress ${ }^{39}$; secondly because $p$ and $\mathbf{P} p$ are simply two different formulae (and not even equivalent); and thirdly because the fact-sameness holds between facts in different tense-logical systems, not within one such system.

These problems can be solved if $p$ and $\mathbf{P} p$ are not taken as fundamental. There are, then, two options. First, one might read them as two perspectivally different presentations of an underlying atemporal fact (say, $p$-at- $t$ ): that amounts to a reductive, B-theoretic underpinning of the tensed facts. Alternatively, one might read them as different presentations of an underlying temporal fact: that takes us back from Prior's tense logic to the original view itself. (In the next section below, I will briefly sketch this latter view.)

Rödl is thus making the point that, if we take Prior seriously when he says that tense logic is 'metaphysically fundamental' (Prior and Fine 1977, p. 37), then there cannot be, amongst the tensed facts themselves, a system into which the 'totalities of tensed propositions which are true at different instants fit together', as Prior claims. ${ }^{40}$ An understanding of tense along the lines of Prior's tense logic is thus incapable of uniting them across time. The lack of cross-temporal unity I observed in the previous section (and above) finds its source in this peculiarity of Prior's tense logic. Fine's analysis of versions of A-theory illustrates the point quite faithfullyin particular his non-standard A-theories: how the relativist's many realities and the fragmentalist's many fragments fit together into a system is never discussed by him.

Now, on the original view, a temporal truth will not be restricted to the present tense: that same truth turns up in past-tense guise at a later moment. Indeed, to say that it is a temporal truth is to say that this contrast of present and past applies to it. Yet on the Priorian understanding of tense under discussion, present-tensed propositions are basic, and the other tenses are understood as constructions on their basis, using certain modal operators. Compare modal propositions, which are, on a reductive view on modality, to be understood as constructions out of a-modal propositions and modal operators. Hence, as Rödl observes:

[If] a present tense formula is elementary, then the contrast to the corresponding past tense formula is not part of its [content], and without this contrast, "present" has no temporal meaning. (Rödl 2012, p. 107)

That is why Bourne's ersatzist version of negative presentism collapses into an eternalist understanding of a temporally thin reality. He may say that his $u$ -

\footnotetext{
39 As Wittgenstein notes in Zettel 693, the problem of an infinite regress is not so much its infinity but rather its disabling any understanding of its members. See Wittgenstein (1967), and see also Rödl (2007, p. 25).

40 To be sure, a more sympathetic reading of Prior would take him to be saying that what tense logic aims to capture is metaphysically fundamental. Rödls's observation then merely indicates that tense logic as is does not fulfill this aim.
} 
propositions are present-tensed, but his Priorian understanding of tense prevents him from actually getting at the temporal form of predication.

Unfortunately, for Prior, his heroic attempt at a rigorous and non-reductive account of time turns out to provide very sophisticated materials for unorthodox reductive takes on temporal thoughts that resemble the temporal form of predication to such an extent that they confuse even those with strong anti-reductionist leanings (such as Prior himself, and Fine). ${ }^{41}$

I have introduced negative presentism, and collected some observations to show that it amounts to no more than an alternative to orthodox, eternalist reductionism. In doing so, I have also uncovered the key to a positive presentism, a version of presentism that really gets us out of the reductionist's desert landscapes and into the full jungle of the original view. The key is a proper understanding of the temporal form of predication: one that is inherently dynamic, and hence makes nonsense of the very attempt to tie temporal truths to locations on a time line (be it a real or an ersatz one). In other words, the key is the temporal form of predication itself. ${ }^{42}$

\section{Original Time Revisited}

I have looked at versions of endurantism, A-theory, and presentism that turned out to be mere variations of a reductive understanding of time in terms of the atemporal form of predication. Along the way, I criticized popular ingredients of such viewsin particular, Prior's tense logic. I should stress that my survey was in no way intended to be comprehensive. How extant varieties of endurantism, A-theory and presentism are to be classified-as 'unorthodox' versions of the reductive approach, or rather as versions of the original view-remains an open question. As said, it was my aim to contribute to a better understanding of the relevant debates, not to settle things one way or another in all cases.

That said, I should say something about the sense in which presentism, A-theory, and endurantism relate to the original view. As my discussion has made clear, we can only do so if we consider how these three elements of the original view can be developed on its own basis-on the basis of the temporal form of predication, that is.

Consider, one after the other, sentences $\mathrm{A}$ and B:

A Your eyes are fixed on sentence A.

B Your eyes were fixed on sentence A.

While you were reading sentence $\mathrm{A}$, sentence $\mathrm{A}$ was true. Then you moved on to reading sentence $\mathrm{B}$ : $\mathrm{B}$ was also true. $\mathrm{A}$ and $\mathrm{B}$ were subsequently true: when $\mathrm{A}$ was

\footnotetext{
${ }^{41}$ Here, I should also include Merricks, who, despite rejecting the temporal-location view of temporal existence (as I noted in fn. 35 above), still adheres to the Priorian time-relative understanding of tensed truths. Indeed, he seems to treat the time-relativity of temporal truths to be definitive of presentism-see Merrick (2007, p. 75).

${ }^{42}$ In my (2016), I have attempted to apply considerations such as the ones sketched in this section to the current debate on how best to define presentism.
} 
true, B was not yet true. Still, they expressed the very same temporal truth: that your eyes were fixed on sentence A. The sentences express different truths (or falsehoods) on different occasions, and hence can be said to vary in truth value across time. But the truths (and falsehoods) themselves remain true (and false) - the facts, of course, don't change. It's just that time passes, and its passage consists in temporal truths being the sorts of truths they are: dynamic. That is the kernel of truth in Prior's tense-based conception of passage, which I mentioned in Sect. 5 above. $^{43}$

Now, first, temporal truths are temporal because of the special form of predication that they involve. Thus, the original view includes A-theory, albeit in a perhaps unusual way. Secondly, such temporal truths do not earn their status as temporal by occupying a location on a time line. Rather, the latter notion is an abstraction from the nature of temporal truth-one that makes it (usefully) suitable for formal modeling, we may add. ${ }^{44}$ Thus, the original temporal nexus includes presentism - not in the negative sense defined in the previous section in terms of erasing part of the time line, but in a positive sense that replaces the reductive time line picture with the dynamic unity of temporal truths. ${ }^{45}$

To get to the third conclusion-that the original temporal nexus includes endurantism-we need to take into account the aspectual characteristic of the temporal form of predication, to which the formal concept of process corresponds, in order to see that such process requires constancy. Consider, one after the other, sentences $\mathrm{A}^{\prime}$ and $\mathrm{B}^{\prime}$ :

\section{$\mathrm{A}^{\prime}$ You are reading sentence $\mathrm{A}^{\prime}$. \\ $\mathrm{B}^{\prime}$ You have read sentence $\mathrm{A}^{\prime}$.}

It is you (and sentence $\mathrm{A}^{\prime}$ ) who remains constant through the described process of taking in sentence $\mathrm{A}^{\prime}$. Although a further exploration of process and related causal concepts on the basis of the original temporal nexus lies beyond the scope of the present paper, we can already see that a sense in which temporal objects are

\footnotetext{
43 In other words: whether or not something is true is, fundamentally, an atemporal matter. Truths don't cease to be true. As we noted, on Prior's tense logic truth is time-relative, as is made explicit in that its model-theory requires a moment as a parameter of truth. That is how it isolates tense from its crosstemporal sameness, as I observed. For a powerful defense of this understanding of temporal truth, see Rödl (2012, esp. ch. 2, §2). That defense is criticized by Friebe (2012, §I.A.2.1), who follows Mellor (1998, p. 30) in concluding from the suggestion that a pair of tensed sentences such as A and B express the same truth, that that truth has to be a B-theoretic truth. That, however, merely shows how entrenched the assimilation of temporal predication with Prior's tense logic has become: if truth is not time-relative, then only B-theory remains. And that is a non sequitur.-Of course, the above merely shows that the temporal form of predication requires the passage of time; it does not properly develop that idea.

44 There are interesting things to say on the relations between models of tense logic (such as branching times) and temporal reality itself - things that bear on the relation between formal modeling and the original temporal nexus. See Pooley (2013, §VI, esp. p. 339) for some elucidating considerations.

45 The truthmaker argument thereby loses its bite. In fact, the original temporal nexus invites a rather unusual but quite literal kind of 'truthmaker theory': as time passes, more and more statements are made true or false-in the sense that things get settled one way or the other. Once made true, these truths remain true: truth itself is atemporal. Note that this implies that, although there are no future contingent truths, all the future necessities are already made true.
} 
'diachronically identical' emerges. Thus, the original temporal nexus includes endurantism. ${ }^{46}$

I have elaborated and defended my thesis: that the fundamental issue to which various debates in the metaphysics of time can be brought back is the question whether we should accept as basic the original temporal nexus, or rather go for a reductive analysis of that conceptual nexus in terms of the atemporal form of predication. If my considerations are on the right track, it is clear that those debates can be more fruitfully pursued when viewed explicitly in this light. In particular, the paradigms that many opponents of orthodox four-dimensionalist reductionism frequently allude to, such as Prior's tense logic, should be critically re-assessed in order to clarify their relationship to the original view and to the reductive project.

Open Access This article is distributed under the terms of the Creative Commons Attribution 4.0 International License (http://creativecommons.org/licenses/by/4.0/), which permits unrestricted use, distribution, and reproduction in any medium, provided you give appropriate credit to the original author(s) and the source, provide a link to the Creative Commons license, and indicate if changes were made.

\section{References}

Asay J, Baron S (2014) The hard road to presentism. Pac Philos Q 95(3):314-335

Ayer AJ (1956) The problem of knowledge. Penguin Books, London

Baia A (2012) Presentism and the grounding of truth. Philos Stud 159(3):341-356

Baron S (2012) Presentism and causation revisited. Philos Pap 41(1):1-21

Baron S (2013) Talking about the past. Erkenntnis 78(3):547-560

Baron S (2015) Tensed truthmaker theory. Erkenntnis 80(5):923-944

Bickhard MH (2011a) Does process matter? An introduction to the special issue on interactivism. Axiomathes 21:1-2

Bickhard MH (2011b) Some consequences (and enablings) of process metaphysics. Axiomathes 21:3-32

Boccardi E (2015) If it ain't moving it shall not be moved. Topoi 34(1):171-185

Bourne C (2006) A future for presentism. Clarendon Press, Oxford

Broad CD (1923) Scientific thought. Routledge \& Kegan Paul, London

Callender C (2002) Time, reality \& experience. Cambridge University Press, New York

Caplan B, Sanson D (2011) Presentism and truthmaking. Philos Compass 6(3):196-208

Chalmers DJ (2012) Constructing the world. Oxford University Press, New York

Chisholm RM (1990a) Events without times: an essay on ontology. Noûs 24(3):413-427

Chisholm RM (1990b) Referring to things that no longer exist. Philos Perspect 4:545-556

Correia F, Iacona A (2013) Around the tree: semantic and metaphysical issues concerning branching and the open future. Springer, Dordrecht

Craig WL (2000) The tensed theory of time. Kluwer, Dordrecht

Crisp TM (2004) On presentism and triviality. In: Zimmerman (2004), chapter 2, pp 15-20

Crisp TM (2007) Presentism and the grounding objection. Noûs 41(1):90-109

De Clerq R (2006) Presentism and the problem of cross-time relations. Philos Phenomenol Res 72(2):386-402

Dowty D (1977) Toward a semantic analysis of verb aspect and the english 'imperfective' progressive. Linguist Philos 1(1):45-77

\footnotetext{
${ }^{46}$ The account of time's passage that is included in the original view also requires us to take its aspectual characteristic into account. Boccardi $(2015, \S 6)$ seems to realize this: he concludes that the A-theorist needs an "extra dynamic ingredient" because "[t]he fact ... that different A-theoretic positions are occupied at different times ... is not by itself sufficient to make the world dynamic, regardless of how we construe of A-properties". What is missing is what he calls 'Plato's Principle', which is basically a demand for aspectual differentiation, as I noted in fn. 16 above.
} 
Eddon M (2010) Three arguments from temporary intrinsics. Philos Phenomenol Res 81(3):605-619

Ellis F (2005) Concepts and reality in the history of philosophy: tracing a philosophical error from Locke to Bradley. Routledge advances in the history of philosophy. Routledge, London

Fine K (2005a) Modality and tense: philosophical papers. Oxford University Press, Oxford

Fine K (2005b) Tense and reality. In: Fine (2005a), pp 261-320

Fiocco MO (2007) A defense of transient presentism. Am Philos Q 44(3):191-212

Friebe C (2012) Zeit - Wirklichkeit - Persistenz: Eine präsentistische Deutung der Raumzeit. Mentis, Paderborn

Geach PT (1966) Some problems about time. In: Proceedings of the British Academy, LI, pp 321-336

Haslanger S (1989) Endurance and temporary intrinsics. Analysis 49:119-125

Hawley K (2002) How things persist. Oxford University Press, New York

Hinchliff M (2000) A defense of presentism in a relativistic setting. Philos Sci 67(3):575-586

Johnston M (1987) Is there a problem about persistence? Proc Aristot Soc Suppl Vol 61:107-135

Lewis DK (1979) Attitudes De Dicto and De Se. Philos Rev 88(4):513-543

Lewis DK (1986) On the plurality of worlds. Blackwell, Oxford

Lewis DK (1991) Parts of classes. Blackwell, Oxford

Lewis DK (2002) Tensing the copula. Mind 111(441):1-13

Lowe EJ (1987) Lewis on perdurance versus endurance. Analysis 47:152-154

Lowe EJ (1988) The problems of intrinsic change: rejoinder to Lewis. Analysis 48(2):72-77

Lowe EJ (1998) The possibility of metaphysics: substance, identity, and time. Oxford University Press, Oxford

Markosian N (1993) How fast does time pass? Philos Phenomenol Res 53(4):829-844

Markosian N (2004) A defense of presentism. In: Zimmerman (2004), chapter 3, pp 47-82

Markosian N (2013) The truth about the past and the future. In: Correia and Iacona (2013), pp 127-142

McCall S (1994) A model of the universe. Clarendon Press, Oxford

McTaggart JME (1908) The unreality of time. Mind 17(68):457-474

Mellor DH (1981) Real time. Cambridge University Press, Cambridge

Mellor DH (1998) Real time II. Routledge, London

Merricks T (1994) Endurance and indiscernibility. J Philos 91(4):165-184

Merricks T (1999) Persistence, parts, and presentism. Noûs 33(3):421-438

Merricks T (2007) Truth and ontology. Oxford University Press, New York

Mulder JM (2012) What generates the realism/anti-realism dichotomy? Philosophica 84:49-80

Mulder JM (2013) The essentialist inference. Australas J Philos 91(4):755-769

Mulder JM (2014) Conceptual realism. Quaestiones Infinitae, LXXXI. Dissertation (at Utrecht University)

Mulder JM (2016) Defining original presentism. Kriterion, Advance Online (August 9, 2016)

Oaklander LN (1991) A defence of the new tenseless theory of time. Philos Q 41(162):26-38

Oaklander LN, Smith Q (1994) The new theory of time. Yale University Press, New Haven

Pooley O (2013) Relativity, the open future, and the passage of time. Proc Aristot Soc 113(3):321-363

Prior AN (1957) Time and modality. Oxford University Press, Oxford

Prior AN (1967) Past, present and future. Oxford University Press, Oxford

Prior AN (1968a) Changes in events and changes in things. In: Prior (1968b), chapter 1, pp 1-14

Prior AN (1968b) Papers on time and tense. Oxford University Press, Oxford

Prior AN, Fine K (1977) Worlds, times and selves. University of Massachusetts Press, Amherst

Quine WV (1960) Word and object. The MIT Press, Cambridge

Reichenbach H (1947) Elements of symbolic logic. Macmillan, New York

Rescher N (1996) Process metaphysics: an introduction to process philosophy. State University of New York Press, Albany

Rescher N (2000) Process philosophy: a survey of basic issues. University of Pittsburgh Press, Pittsburgh

Rödl S (2007) Self-consciousness. Harvard University Press, Cambridge

Rödl S (2012) Categories of the temporal: an inquiry into the forms of the finite intellect (trans: Salewski

S). Harvard University Press, Cambridge

Russell B (1915) On the experience of time. Monist 25(2):212-233

Russell B (1919) The philosophy of logical atomism. Monist 29(1):32-63

Russell B (1941) An inquiry into meaning and truth. George Allen \& Unwin Ltd., London

Rychter P (2008) Perdurance, endurance, and 'having a property atemporally'. Metaphysica 9(2):159-171

Sellars WS (1981a) Foundations for a metaphysics of pure process, I: the lever of archimedes. Monist 64(1):3-36 
Sellars WS (1981b) Foundations for a metaphysics of pure process, II: naturalism and process. Monist 64(1):37-65

Sellars WS (1981c) Foundations for a metaphysics of pure process, III: is consciousness physical? Monist 64(1):66-90

Sider T (2001) Four-dimensionalism: an ontology of persistence and time. Oxford University Press, New York

Sider T (2012) Writing the book of the world. Oxford University Press, New York

Sider T, Hawthorne J, Zimmerman DW (eds) (2008) Contemporary debates in metaphysics. Wiley, Malden

Skow B (2009) Relativity and the moving spotlight. J Philos 106(12):666-678

Smart JJC (1963) Philosophy and scientific realism. Routledge \& Kegan Paul, London

Smith Q (1993) Language and time. Oxford University Press, New York

Smith Q (2002) Time and degrees of existence: a theory of “degree presentism”. In: Callender (2002), pp 119-136

Tallant JC (2014) Defining existence presentism. Erkenntnis 79(3):479-501

Thompson M (2008) Life and action. Harvard University Press, Cambridge

Torrengo G (2013) The grounding problem and presentist explanations. Synthese 190(12):2047-2063

Torrengo G (2014) Ostrich presentism. Philos Stud 170(2):255-276

van Inwagen P (1990) Four-dimensional objects. Noûs 24(2):245-255

van Inwagen P, Zimmerman DW (1998) Metaphysics: the big questions. Blackwell, Malden

Whitehead AN (1929) Process and reality. Cambridge University Press, Cambridge

Williams DC (1951) The myth of passage. J Philos 48(15):457-472

Williamson T (2013) Modal logic as metaphysics. Oxford University Press, Oxford

Wittgenstein L (1967) Zettel (trans: Anscombe GEM). University of California Press, Berkeley and Los Angeles

Zimmerman DW (1998) Temporary intrinsics and presentism. In: van Inwagen and Zimmerman (1998), chapter 25, pp 206-219

Zimmerman DW (ed) (2004) Oxford studies in metaphysics, vol 1. Clarendon Press, Oxford

Zimmerman DW (2005) The A-theory of time, the B-theory of time, and 'taking tense seriously'. Dialectica 59(4):401-457

Zimmerman DW (2008) The priviledged present: defending an "A-theory" of time. In: Sider et al. (2008), chapter 5.1, pp 211-225 